\title{
Practical Demonstrations - Key to Efficient Explanations of Radioactivity to Pupils and Students
}

\author{
Matjaž Koželj \\ Milan Čopič Nuclear Training Centre \\ Jožef Stefan Institute \\ Ljubljana, Slovenia \\ matjaz.kozelj@ijs.si
}

\author{
Vesna Slapar Borišek \\ Milan Čopič Nuclear Training Centre \\ Jožef Stefan Institute \\ Ljubljana, Slovenia \\ vesna.slapar-borisek@ijs.si
}

\author{
Radko Istenič \\ Milan Čopič Nuclear Training Centre \\ Jožef Stefan Institute \\ Ljubljana, Slovenia \\ radko.istenic@ijs.si
}

\begin{abstract}
The radioactivity workshop and hands-on demonstrations in Milan Čopič Nuclear Training Centre enable us to effectively transfer some basic information about radioactivity, radiation and radiation effects to our young visitors. This activity has been well accepted and praised by teachers, who are aware of the subject importance for education.
\end{abstract}

Keywords - radioactivity, demonstrations, workshop, pupils, students.

\section{INTRODUCTION}

Milan Čopič Nuclear Training Centre (ICJT), which is part of Jožef Stefan Institute (J SI), L jubljana, was founded in 1989 to support training of Krško NPP workers. Since then, number of courses for control room staff and other technical personnel were prepared and implemented. Courses are also intended for members of technical support organisations, authorities and experts employed by Krško NPP subcontractors. ICJT also organise different courses and events in cooperation with international organisations or agencies like IA EA, ENS or EC.

Soon after successful conclusion of the initial courses, the decision has been made to expand our activities. A that time, the public opinion in Slovenia was still heavily influenced by Chernobyl accident and there were debates in media and among politicians about danger of nuclear energy and about the necessity to close Krško NPP. Explanations and clarifications related to safety of our plant provided by nuclear professionals were originally targeted to decision makers, and less to opinion makers. The information was presented and distributed within limited circles, also due to the limited interest of majority of media for, what was called at that time, "biased" opinion of nuclear experts.

Our aim was not to join those discussions, but to approach general public and to contribute to general opinion on long term basis. Since we were aw are that the discussion on nuclear energy would follow into the following years, we have decided to establish nuclear technology information centre with permanent exhibition of nuclear technology. The vision was to become reliable and respected source of knowledge about nuclear technologies for general public. Since we had free basement at our premises, we were able to commission big lecture room and exhibition with posters and few mockups (Fig. 1) without huge investments and lasting constructions.

At the beginning (in the mid-nineties), emphasise was given to the Krško NPP technology and operation, but later a part related to radioactive waste management was added to the exhibition. In the recent decade, exhibition was complemented with overview of nuclear fusion technology research.

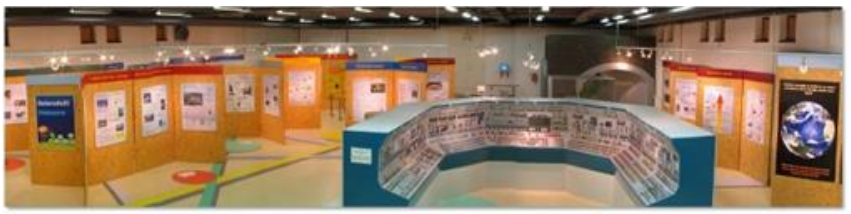

Fig. 1. Exhibition in nuclear technology information centre.

From the very beginning of the information centre operation, our most numerous and regular visitors are pupils and students from primary and secondary schools in Slovenia. In addition, other groups visit our centre - groups of university students, teachers, members of different professional associations, firefighters, groups of retirees, etc. A nnually, our information centre visit more than 150 groups and more than 6500 visitors. A Itogether, more than 3,500 school groups and more than 180,000 pupils, students, teachers and other persons visited our information centre since 1993 [1].

The exhibition was usually short addition to the lecture for our visitors at the beginning of information centre operation. Posters with information were prepared to support lectures with some additional data or visual material, and to provide explanation of some concepts from physics or engineering which are important for understanding of NPP operation. At that time, we have discovered that is that explanations of basic concepts of radioactivity and ionising radiation have de facto disappeared from school programmes. They were either pushed in schedule somewhere at the end of school year, in parallel with final exams like a filler, or were considered optional, leaving decision on presenting these contents to individual teacher.

It was also obvious that majority of teachers are not competent to speak about these subjects and that they are prone to avoided it. Radioactivity used to be one of the subjects discussed in Physics classes, but was later added to Chemistry classes. It would work in "old" times, but after Chernobyl accident radioactivity and ionising radiation were considered result of reactor operation and considering the consequences of accident, also extremely dangerous. The other problem was that just few schools had any equipment that can be used for classroom demonstration, and even if they had the equipment, teachers did not know how to use it properly.

What we have learned is that if we want to effectively transfer messages to our visitors, especially pupils and students, and if we want them to become active subjects in 
debates and decision process related to nuclear energy in Slovenia, we have to provide them with basic information about radioactivity, radiation and radiation effects to human beings. This knowledge should serve as a basis for evaluation and judgment of problems and questions that must be resolved if we want to continue living with nuclear energy in near future.

We felt that adding or expanding existing lectures would not be productive, and we decided to add some hands-on experiments and to prepare small radioactivity workshop with practical demonstrations of ionising radiation properties, demonstration of natural background radiation and radon. We were also considering idea to prepare hands-on experiments for all our demonstrations, but it would be costlier and we also had to comply with limited time that participants spent at our site. Therefore, we came to conclusion that the most effective approach would be to combine hands-on experiments at the exhibition with practical demonstrations in radioactivity workshop and to complement demonstrations with physical background explanation.

\section{HANDS-ON EXPERIMENTS AND DEMONSTRATIONS}

\section{A. Main Goals}

There are two main goals behind hands-on experiments and demonstrations: first, we want to inform visitors that radioactivity is something natural and present everywhere in our environment, and second, we want to convince them that we know how to protect from excessive radiation.

The first message is the most important, since awareness of natural sources of radiation and the resulting exposure is essential for understanding of and discussion about the effects of ionising radiation in general. This is important not only when operation of existing (or planned) nuclear and radiation facilities are discussed and evaluated, but even more important when accidents occur, like the last one in Fukushima.

The importance of the second goal is related to acceptance of all radioactive sources, including nuclear or radiation facilities.

\section{B. Approach and Design [2]}

When we were designing exhibits and demonstrations our wish was to make them simple and attractive. Therefore, we decided to limit to basic information, which could be given in a short time (a few seconds!), without extensive explanation. Hands-on experiments should be self-explanatory (minimal necessary information should be written on the exhibit!) and visitors should be involved in experiment (they should "discover" information).

All instruments used should be very sensitive and must be equipped with loud acoustic indication (instrument read-outs are of minor importance), and only rate (counts per second or counts per minute) is allowed if some measurement result should be given. Abstract quantities, like dose, should be avoided. Old-fashioned detectors with End Window GM tubes and analogue displays satisfy these requirements and are used for demonstrations. For larger (and "noisier") groups of visitors, we use small web camera to project the instrument read-outs on the big TV screen.

For the hands-on experiments we use modern handheld instruments with sensitive pancake GM tubes and big digital displays as rate meters, but also with acoustic and optical (flashing light) indication.

\section{Hands-on experiments}

Two exhibits were originally prepared, one directly related to the demonstration of radioactivity, and the other more like a "teaser". The first exhibit is the radioactivity carousel, where different samples from the environment (fertiliser, potassium chloride, a watch with luminous dials, uranium glass, welding rods, gas mantle and an empty place - for background) are fastened on a round plate (Fig. 2). Visitors turns the plate and observe instrument response. Finding the most radioactive sample is a usual game that visitors play with the carousel, but neverthel ess they al so remember other samples. The carousel has also been copied (with our permission) as an applet on the Nucleonica.com site [3].

The second exhibit is just an instrument positioned above a table. Visitors can "measure" their own items, to check whether they are radioactive. A s could be expected, nowadays the instrument is mostly used for checking mobile phones (Fig. 3).

Recently, we have also added two new historical exhibits: one exhibit is therapeutic ${ }^{226} \mathrm{R}$ a source from the beginning of the twentieth century (Fig. 4), the oldest artificial radioactive source in Slovenia, which was donated by Faculty of Medicine, Ljubljana. The second exhibit are samples of uranium compounds (Fig. 5) prepared during pilot production of yellow cake in the 1980s at Jožef Stefan Institute, Ljubljana.

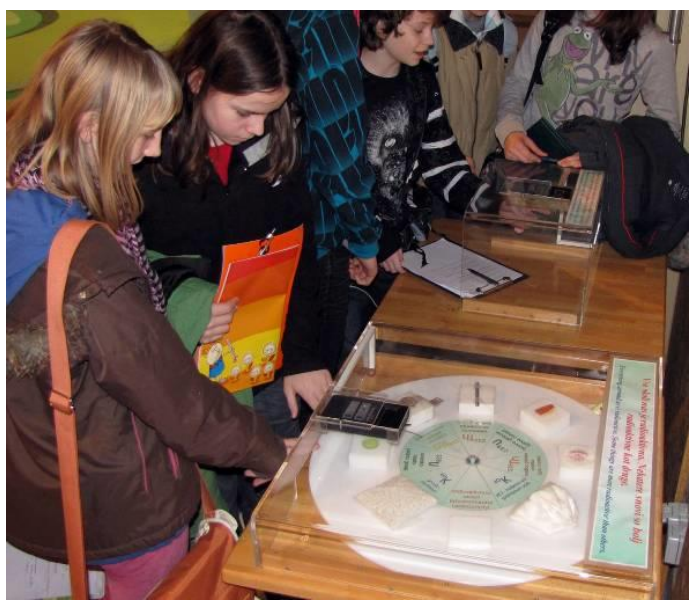

Fig. 2. Radioactivity carousel.

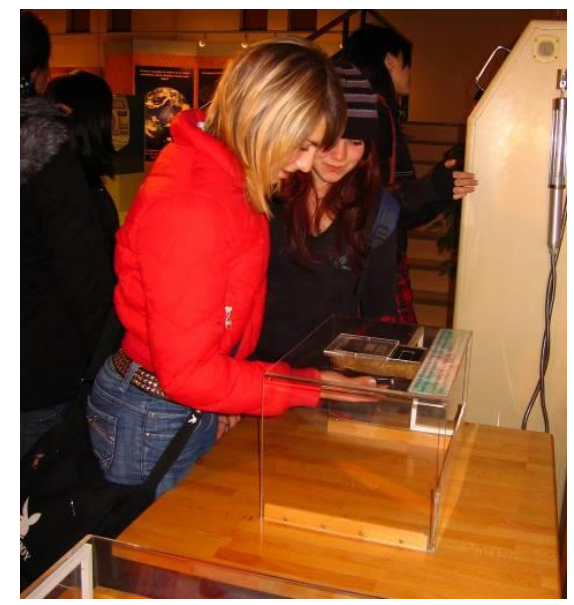

Fig. 3. Instrument for visitors. 


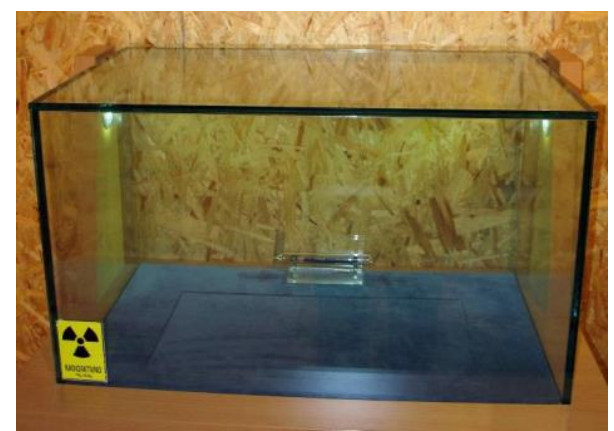

Fig. 4. Historical source: Therapeutic ${ }^{226}$ Ra source.

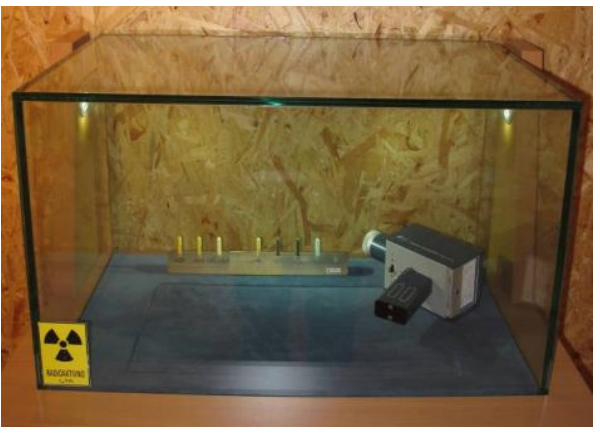

Fig. 5. Samples of uranium compounds.

\section{Radioactivity Workshop [2]}

Demonstrations in the radioactivity workshop are intended to familiarise visitors with basic properties of radiation and principles of protection. The workshop takes place in a separate classroom with benches and a demonstration table with the measurement equipment. The walls of the classroom are covered with posters with some basic facts about radiation in support of the lecturer's explanations.

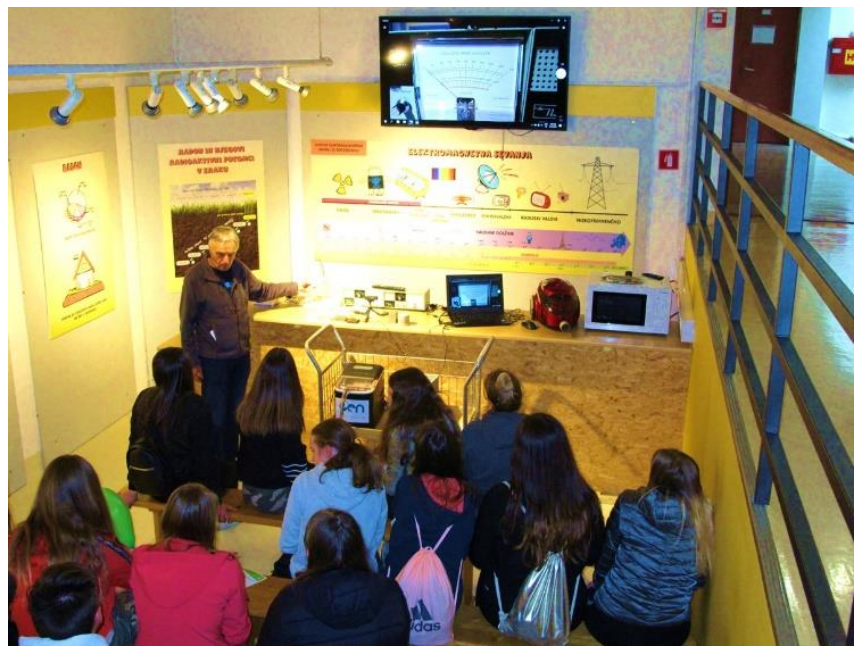

Fig. 6. Radioactivity workshop in Nuclear Technology Information Centre.

Three separate measurement stations were installed, each with a ratemeter and a sensitive End Window GM tube on a carrier which assures better visibility. Stations are dedicated to experiments with $\alpha, \beta$ and $\gamma$ radiation.

Absorbers were prepared for each station: paper, cardboard ( $1 \mathrm{~mm})$, and aluminium foil $(10 \mu \mathrm{m})$ for $\alpha$ radiation, cardboard (1 mm), aluminium plates $(0.5 \mathrm{~mm})$, and acrylic glass plates $(5 \mathrm{~mm})$ for $\beta$ radiation, and half-value layers of lead $(10 \mathrm{~mm})$, steel $(16 \mathrm{~mm})$, aluminium $(45 \mathrm{~mm})$ and concrete $(70 \mathrm{~mm})$ for $\gamma$ radiation. Special rulers with visible marks were also prepared for demonstration of the range of $\alpha$ radiation in air and dose-to-distance dependency for $\gamma$ radiation.

For demonstrations we use pure sources: ${ }^{210} \mathrm{Po}$ as $\alpha$ source, ${ }^{90} \mathrm{Sr}$ as $\beta$ source, and ${ }^{60} \mathrm{Co}$ (with $\beta$ shield) as $\gamma$ source. It is important not to use mixed sources to avoid additional unconvincing explanations and justifications. All sources are school sources below exemption level - low activity is compensated with sensitive detectors. We also use an additional check sources - an old watch with luminous dials, similar to the watch on the radioactivity carousel, and Th-enriched T ungsten welding rods.

W ith this equipment we can demonstrate:

1) Natural background,

2) Absorption and range of $\alpha$ radiation in air, paper, and aluminium,

3) Absorption and range of $\beta$ radiation in in cardboard, aluminium and acrylic glass,

4) Attenuation and half-value layers for $\gamma$ radiation,

5) Dependency of count (dose) rate over distance,

6) Demonstration of radon progeny,

The intention of these demonstrations is to illustrate basic properties and differences between $\alpha, \beta$, and $\gamma$ radiation, and also to convince visitors that we know how to measure radiation and how to protect from it.

There is al so one less sophisticated item in the classroom: an ordinary vacuum cleaner. We use it to demonstrate the presence of radon progeny in the air. Due to the elevated concentration of radon in the exhibition hall (it is in the basement of ICJT), it is possible to collect significant activity of radon progeny on a plain kitchen filter within a few minutes by pumping with the vacuum cleaner. The collected activity is usually much higher than the activity of the $\alpha$-source, which is al ways a huge surprise for visitors.

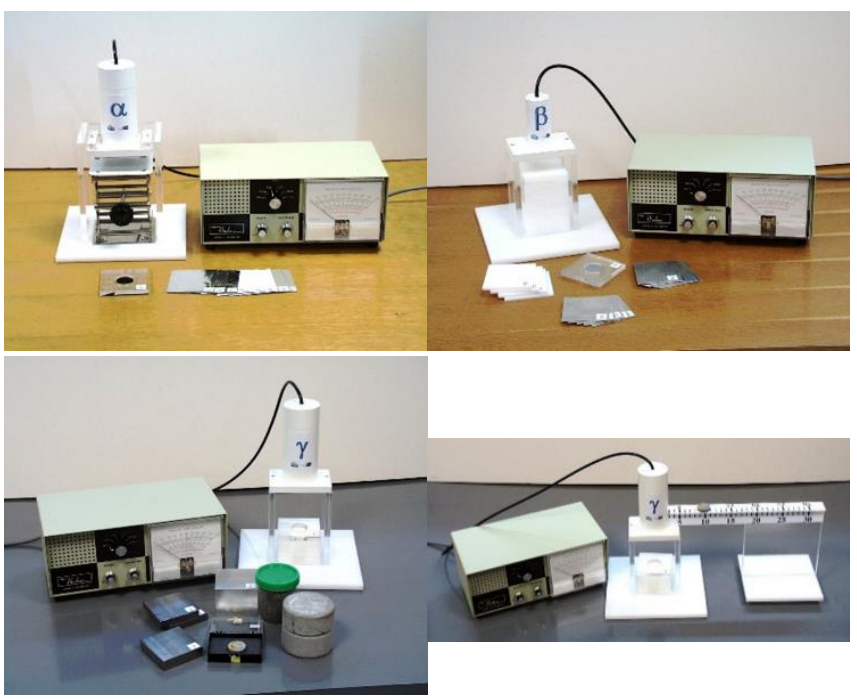

Fig. 7. Equipment for demonstration of radiation properties. 

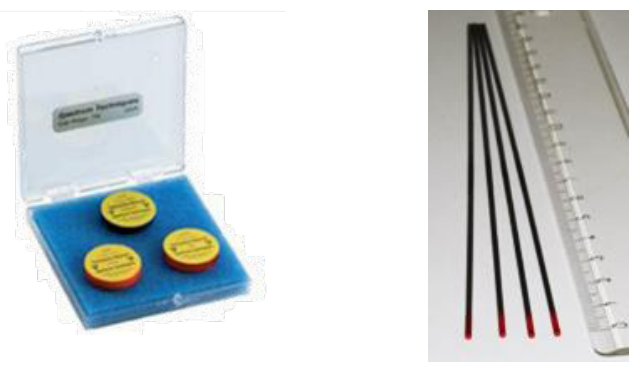

Fig. 8. Exempted sources are used for demonstrations.

There is even more "unusual" experimental gadget in the workshop: we use simple toy balloon for collection of radon progeny. After inflation, the surface of balloon becomes charged (some help with woollen rag is beneficial) and successfully collects radon progeny. Again, high radon concentration is helpful and collection of radon progeny in worst case requires no more than five to ten minutes.
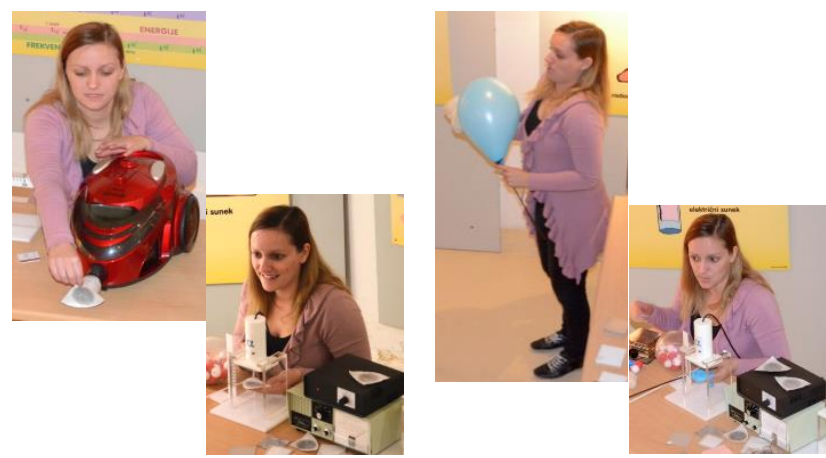

Fig. 9. Demonstration of radon progeny with filter and vacuum cleaner (left) and toy balloon (right).

Recent addition to our workshop is a small Cloud chamber, which we use in combination with web camera and TV screen. $V$ isible traces of charged particles in the chamber on the big TV screen are illustrative support of our explanations about interaction of radiation in matter.

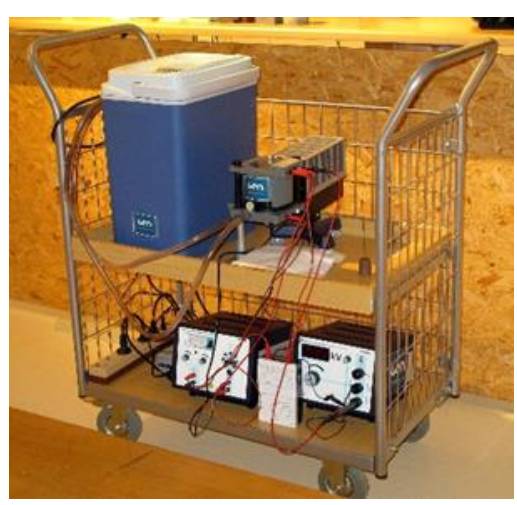

Fig. 10. Cloud chamber with cooler and power supplies.

\section{Response From the Visitors}

A Imost all visitors of our Milan Čopič N uclear Training Centre visit exhibition and radioactivity workshop. M ost of them are teenagers, but we also have younger and also many older visitors, even retirees. Response from almost all visitors is positive, many of them have also express satisfaction for seeing "how things really work".

Our most faithful visitors are teachers who return every year with new groups of pupils or students. Teachers of Physics and Chemistry especially appreciate the radioactivity workshop as an addition to the regular classes. M ost of them learned about radioactivity at U niversity, but have no time and possibility to lecture and demonstrate radioactivity to their students. For other teachers (Biology, M ath, Geography, History...) and students this is usually the first opportunity to observe radiation "at work"

In the radioactivity workshop demonstration of radon progeny is usually the most attractive and surprising. The visitors' reaction is almost always emotional, which also assures that it will stay in their memory. Other demonstrations in workshop are generally intriguing for the students with a more analytical mind and those, who already have some previous knowledge about radioactivity.

From time to time and for special interested groups, usually students from secondary schools, we prepare more advanced workshops where we perform measurements, and not only demonstrations. Although this is more demanding and time-consuming, it is also more rewarding.

\section{CONCLUSIONS}

A number of teachers in el ementary and secondary schools are returning visitors, who consider our workshop and demonstrations valuable addition to their lectures.

We can confirm that "A Picture is Worth a Thousand Words and an Experiment is Worth Fifty Slides" [4]. W e have been very successful and efficient in the transfer of knowledge about radioactivity radiation and radiation effects to our visitors.

Probably one of the most important messages our visitors receive is related to the existence of natural background radiation and radon.

\section{REFERENCES}

[1] M. Koželj, V. Slapar Borišek, "Spreading knowledge on radiation protection in Nuclear technology information centre," in ETRAP 2017 Conference Proceedings, Valencia, Spain, $30 \mathrm{M}$ ay $-2^{\text {nd }}$ J une 2017 , ENS, B russels, 2017

[2] M. Koželj, R. Istenič, "Radioactivity experiments for schools." in Proceedings, 22nd International Conference Nuclear Energy for $\mathrm{New}$ Europe - NENE 2013, Bled, September 9-12., 2013, L. Cizelj, M. Leskovar, and M. Uršič, Eds., Ljubljana, Nuclear Society of Slovenia. 2013, 1313.1-1313.9,

[3] https://www.nucleonica.com/wiki/index.php?title=H elp\%3A Natural Radioactivity, J uly 2019,

[4] S. Landsberger, T. Tipping, W S Charlton, "A Picture is Worth a Thousand Words and an Experiment is Worth Fifty Slides: Development of Experiments in Health Physics to Reinforce Basic Radiation Protection Concepts", Contribution at 8th EUTERP W orkshop, A pril 10-12, 2019, Qawra, St. Paul's Bay, Malta. 